\title{
Eyelid Gnawed Away by all the Layers by the Dog
}

Jacob Matthew ${ }^{1}$,Trenton Dalton ${ }^{1 *}$ and George Francisco ${ }^{1}$

${ }_{1}^{1}$ Department of Dermatology, Hospital of Heraldton, Greece.

* Corresponding Author : Trenton Dalton, Department of Dermatology, Hospital of Heraldton, Greece, Email: tdalton@yahoo.com Received date: July 20, 2017;Accepted date: Au gust 20, 2017; Published date: August 29, 2017.

Citation : Jacob Matthew, Trenton Dalton and George Francisco, Eyelid Gnawed Away by all the Layers by the Dog. J.Dermatology and Dermatitis. Doi: $10.31579 / 2578-8949 / 010$

Copyright : @2017 Trenton Dalton. This is an open-access article distributed under the terms of The Creative Commons Attribution License, which permits unrestricted use, distribution, and reproduction in any medium, provided the original author and source are credited.

\begin{abstract}
An elderly woman had been bedridden for several years, and was neither able to move her limbs or speak. One night, the woman's family forgot that their small canine entered her room and was leaving overnight. Next morning, they discovered that the skin of the woman's right eyelid had been gnawed away by all the layers by the dog.

Keywords: dog bite injury; indoor dog; emergency reconstruction; shih tzu eats an elderly human's eyelid; the brachyrhinia type short nosedog
\end{abstract}

\section{Case Presentation}

An 83 years old woman had been bedridden for several years, and was neither able to move her limbs or speak being at home in local city of Japan. One night, the woman's family forgot that their small canine (Shih Tzu) entered her room and was leaving overnight. When the family went to the room the following morning, they discovered that the skin of the woman's right eyelid had been gnawed away by all the layers by the dog. In our hospital, we could repair the patient's eyelid using a subcutaneous flap (for inner side) and a forehead flap (for outer side) (Figure 1 and 2).

It is a worldwide pet boom. Above all, in Japan, the popularity of the dog is high and the small dog which it is possible to breed seems specifically liked indoors. The small dog is lovely like the small animal and has felt like the animal which is different from the medium or large sized dog but the ancestor is the same wolf. Don't forget being a carnivorous-animal.

Because this patient was bedridden, while licking a dog because it might have thought that it is a moribund game and the leavings of the food adhered to the eyelid, it only may be to have been advanced in the eating. Also, the involvement of the stress which was left by indoors, too, is thought ofAlthough there are many injuries due to dog bites there is no report of the heavy wound by the small dog. It thinks that the bonesof-viscerocranium case of the dog of the brachyrhinia type (short nose dog) like the Shih Tzu doesn't suit an attack, too [1,2]. And then, it will have become the external injury gross result as it takes in the lick. There is possibility that the danger which is same when the indoor dog and the elderly which needs nursing care live at the urban dwelling increases.

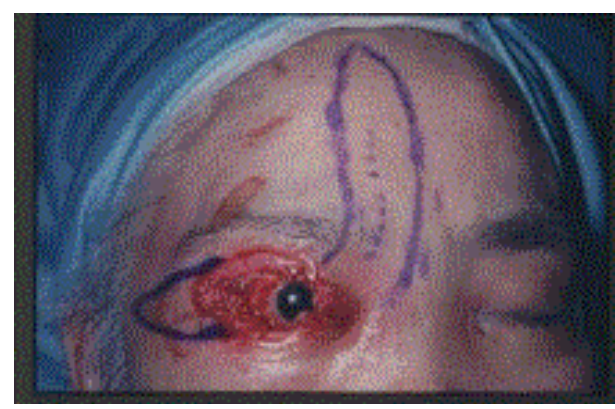

Figure 1 Pre- operation design

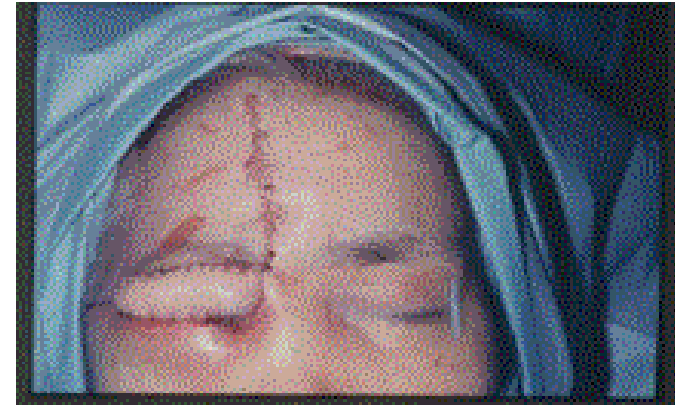

Figure 2 Post-operation

\section{References}

1. Abuabara A. A review of facial injuries due to dog bites. Med Oral Patol Oral Cir Bucal. 2006;11(4):E348-50.

2. Evgeniou E, Markeson D, lyer S, Armstrong A. The management of animal bite in the United Kingdom. Eplasty. 2013;13:E27. 